\title{
Nurses' Knowledge Levels of Chest Drain Management: A Descriptive Study
}

\author{
Merve Tarhan¹, Songül Akbaş Gökduman², Abdülkadir Ayan², Levent Dalar³ \\ ${ }^{1}$ Department of Nursing, İstanbul Medipol University School of Health Sciences, İstanbul, Turkey \\ ${ }^{2}$ Clinic of Emergency Service, Yedikule Chest Diseases and Chest Surgery Training and Research Hospital, İstanbul, Turkey \\ ${ }^{3}$ Department of Chest Diseases, İstanbul Bilim University School of Medicine, İstanbul, Turkey
}

\begin{abstract}
Objective: The physician is responsible for inserting one or more chest tubes into the pleural space or the mediastinal space and connecting them to an appropriate drainage system. When the general principles about care of patients with chest drains were implemented correctly and effectively by nurses, nurse will contribute to accelerate the healing process of patients. In this context, the aim of this study was to determine the nurses' level of knowledge regarding the care of patients with chest drains.

Methods: The study was conducted with 153 nurses who worked in a chest diseases and thoracic surgery hospital in July 2014. Questionnaire form of 35 questions prepared by investigators was used to collect data. For the analysis of results, frequency tests, independent sample t-test and oneway ANOVA test were used.

Results: $69.3 \%$ of nurses stated that they had obtained information from colleguages. $35.3 \%$ considered their knowledge about chest drain management to be inadequate. $55.6 \%$ scored 13 points and above from knowledge questionnaire about chest drain management. There were statistically significant difference between knowledge level and educational background, clinic work type, working unit, years of professional experience and institutional experience, frequency of contact patients with chest drain and perception of knowledge level ( $\mathrm{p}<0.05)$.

Conclusion: Results of this study indicate that lack of evidence-based nursing care and insufficient training has resulted in uncertainty and knowledge deficit in important aspects of chest drain care. It can be concluded that nurses receive training needs and training protocols are about chest drain management.
\end{abstract}

Keywords: Chest drain, knowledge, nursing, patient care, thoracic surgery

Received Date: 08.07.2015 Accepted Date: 14.06.2016 Available Online Date: 05.09.2016

DOI: 10.5152/ejp.2016.97269

Correponding Author Merve Tarhan

E-mail: mtarhan@medipol.edu.tr

- Available online at www.eurasianjpulmonol.com

This work is licensed under a Creative Commons Attribution-NonCommercial 4.0 International License.

\section{INTRODUCTION}

Chest drainage is defined as discharging air, water, blood, and other fluids by inserting a tube into the pleural or mediastinal cavity. Chest drainage is generally used in the treatment of patients who have undergone heart and chest surgery or chest trauma (1).

Chest drainage is an invasive operation; insufficient knowledge and experience of the healthcare team may lead to unwanted complications (2). The mismanagement of chest drainage may cause series of complications such as increased morbidity, extension of duration of hospital stay, and even death in some cases (3).

The insertion of a chest tube in a patient using the aseptic technique is the physician's responsibility. However, as long as the chest tube is kept inserted, the nurses' responsibilities include (i) monitoring the drainage bottle and suction level, (ii) recording the quantity and content of drainage, (iii) administering wound care and follow-up of pain, and (iv) providing information and support to the patient (4). The applications involving these aspects of nursing in the management of patients with chest tubes are inconsistent, which leads to distrust regarding nurses during patient care (5). 
To the best of our knowledge, no study in Turkey has researched the knowledge levels of nurses in the management of patients with chest tubes. This study intends to close the gap in the literature regarding the knowledge levels of the nurses working in hospitals dealing with chest diseases, particularly regarding patients with chest tubes.

\section{METHODS}

This descriptive study was conducted with nurses working in a hospital in Istanbul dealing with chest diseases in August 2014. The sample comprised 152 (out of 192) nurses working in the hospital at the time of the study who were not on leave for any reasons and accepted to participate in the study. The participation rate was $79 \%$.

A questionnaire form prepared by researchers reviewing the literature was used for data collection. The form consisted of two parts. The first part collated information on the descriptive and occupational characteristics of nurses and the second part collated information on the nurses' knowledge levels regarding the management of patients with chest tubes. There were 25 expressions in the questionnaire form measuring the knowledge levels of nurses. For these expressions, each true response was evaluated as 1 point and false and unknown responses were evaluated as 0 points. The total points were calculated by adding the points taken from all the true responses. With regard to the number of points from these knowledge questions, the minimum was 0 and the maximum was 25 . The nurses who correctly replied to less than half of the questions were classified as having an insufficient knowledge level, those who correctly replied to $50-75 \%$ of the questions were classified as having an intermediate knowledge level, and those who correctly replied to $75-100 \%$ of the questions were classified as having a sufficient knowledge level. Accordingly, the nurses scoring $\geq 19$ points were certified as having a sufficient knowledge level, those scoring between 13 and 18 points were certified as having an intermediate knowledge level, and those scoring $\leq 12$ points were certified as having an insufficient knowledge level.

The study was conducted in accordance with the Declaration of Helsinki. Written consent of the Istanbul Fatih Secretary General of the Association of Public Hospitals (to which the hospital was affiliated) was obtained before beginning the study. Before joining, the forms were distributed to the nurses only after they were given information about the study and by taking their verbal consent. The questionnaire forms, which took 15-20 minutes to fill, were given to the nurses by the researchers, and the nurses were asked to fill them at an appropriate time.

\section{Statistical Analysis}

Analysis of the results was performed with Statistical Package for the Social Sciences released in 2007 [SPSS for Windows, version 16.0 (SPSS Inc.; Chicago, IL, USA) software]. Categorical variables such as gender and education level were represented as numbers and percentages, respectively; continuous variables such as age and knowledge level were represented as mean and standard deviation, respectively. Since the data exhibited a normal distribution because of applying the Kolmogorov-Smirnov test, t-test was used in independent groups when the mean values of the two independent groups were compared, and one-way analysis of variance was used when the mean values of more than two independent groups were compared. When the decision of significance was made at the end of one- way analysis of variance, Tukey test was used to determine a group or groups with differences. The significance level was set at 0.05 .

\section{RESULTS}

The descriptive and occupational characteristics of the nurses are displayed in Table 1 . Most nurses were female $(80 \%, n=124)$. The mean age was 32.08 years (SD: 8.24), and it varied between 22 and 53 years. Further, $51.6 \%$ of the nurses who participated in the study were working in ward; $18.3 \%$, in emergency; $15.7 \%$, in the intensive care unit; $7.2 \%$, in outpatient clinics; and $7.2 \%$, in the operating room. Moreover, $65.6 \%$ of the nurses were working in internal medicine units. More than half of them held a bachelor's degree (52.9\%). In addition, $35.3 \%$ of the nurses had an occupational experience between 1 and 5 years, and almost half of them had the same institutional experience $(49.7 \%)$. In total, $34.6 \%$ of the nurses stated that they encountered at least one patient with a chest tube every day, and $32.7 \%, 32 \%$, and $35.3 \%$ stated that they perceived their knowledge level about the management of patients with chest tubes as sufficient, intermediate, and insufficient, respectively.

In this study, $69.3 \%, 37.9 \%, 26.1 \%$, and $2.6 \%$ of the nurses stated that they obtained information about the management of patients with chest tubes from their colleagues, from the Internet, from books/ journals, and from school education, respectively (Figure 1).

The mean score obtained from the knowledge questions was 13.8 \pm 5.5 , and the median score was 13 . It was observed that $55.6 \%$ of the nurses scored $\geq 13$ points from the knowledge questions (Figure 2 ).

The distribution of mean scores of the nurses according to their descriptive and occupational characteristics on the basis of the knowledge questions about the management of patients with chest tubes is presented in Table 2. The scores obtained by the female nurses were higher than those obtained by the male nurses; the difference between these scores was not statistically significant $(p>0.05)$. It was found that the nurses having an Associate degree scored higher than those having a bachelor's degree, and the nurses working in surgical units scored higher than those working in internal medicine units; the difference between these scores was statistically significant $(p<0.05)$. The scores of the nurses working in operating rooms were higher than those of the nurses working in general services. The nurses having an occupational experience of 16-20 years scored higher

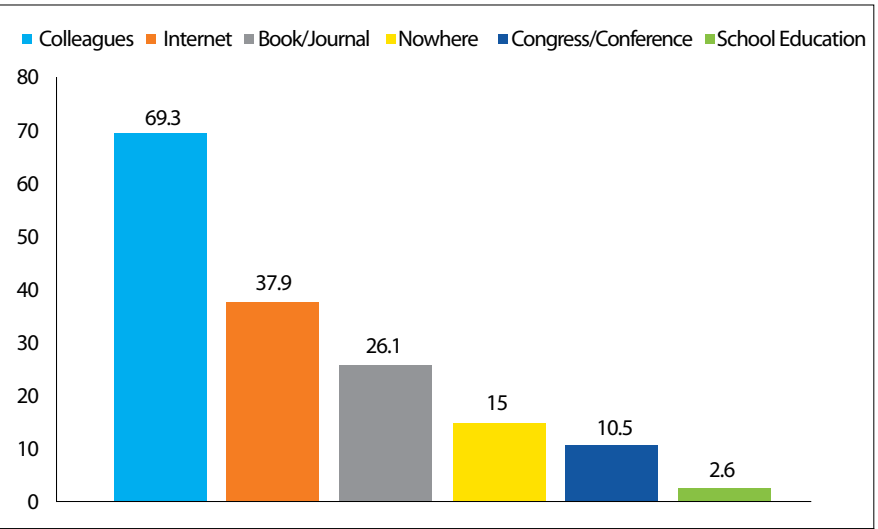

Figure 1. Distribution of resources through which the nurses obtained their knowledge regarding the management of patients with chest tubes 
Table 1. Distribution of descriptive and occupational characteristics of nurses $(n=153)$

\begin{tabular}{|c|c|c|}
\hline Characteristics & $\mathbf{n}$ & $\%$ \\
\hline \multicolumn{3}{|l|}{ Gender } \\
\hline Female & 124 & 81 \\
\hline Male & 29 & 19 \\
\hline \multicolumn{3}{|l|}{ Education level } \\
\hline Medical vocational high school & 29 & 19 \\
\hline Associate degree & 33 & 21.6 \\
\hline Undergraduate & 81 & 52.9 \\
\hline Postgraduate & 10 & 6.5 \\
\hline \multicolumn{3}{|l|}{ Department } \\
\hline Internal medicine & 105 & 68.6 \\
\hline Surgery & 48 & 31.4 \\
\hline \multicolumn{3}{|l|}{ Unit } \\
\hline General services & 79 & 51.6 \\
\hline Emergency service & 28 & 18.3 \\
\hline Intensive care unit & 24 & 15.7 \\
\hline Outpatient clinic & 11 & 7.2 \\
\hline Operating room & 11 & 7.2 \\
\hline \multicolumn{3}{|c|}{ Duration of occupational experience } \\
\hline $1-5$ years & 54 & 35.3 \\
\hline $6-10$ years & 37 & 24.2 \\
\hline $11-15$ years & 20 & 13.1 \\
\hline $16-20$ years & 19 & 12.4 \\
\hline 21 years and over & 23 & 15 \\
\hline \multicolumn{3}{|c|}{ Duration of institutional experience } \\
\hline $1-5$ years & 76 & 49.7 \\
\hline $6-10$ years & 27 & 17.6 \\
\hline $11-15$ years & 15 & 9.8 \\
\hline $16-20$ years & 14 & 9.2 \\
\hline 21 years and over & 21 & 13.7 \\
\hline \multicolumn{3}{|c|}{$\begin{array}{l}\text { Frequency of encountering a patient } \\
\text { with a chest tube }\end{array}$} \\
\hline Everyday & 53 & 34.6 \\
\hline Almost everyday & 21 & 13.7 \\
\hline Once a week & 21 & 13.7 \\
\hline Biweekly & 17 & 11.1 \\
\hline Once a month & 15 & 9.8 \\
\hline Once a year & 10 & 6.5 \\
\hline Never & 16 & 10.5 \\
\hline \multicolumn{3}{|l|}{ Perception of knowledge level } \\
\hline Sufficient & 50 & 32.7 \\
\hline Partially sufficient & 49 & 32 \\
\hline Insufficient & 54 & 35.3 \\
\hline
\end{tabular}

Table 2. Descriptive and occupational characteristics of the nurses and comparison of average points they scored from knowledge questions regarding the management of patients with chest tubes

\begin{tabular}{|l|l|l|l|l} 
Characteristics & Mean & $\begin{array}{c}\text { Standard } \\
\text { deviation }\end{array}$ & $\begin{array}{c}\text { Test } \\
\text { value }\end{array}$ & p
\end{tabular}

\section{Gender*}

Female

Male

Education level ${ }^{* *}$

Medical vocational high school

Associate degree

Undergraduate

Postgraduate

Department*

Internal medicine

Surgery

Unit $^{* *}$

General wards

Emergency ward

Intensive care unit

Outpatient clinic

Operating room

Duration of occupational experience $^{* *}$

$1-5$ years

6-10 years

11-15 years

16-20 years

21 years and over

Duration of institutional experience $^{* *}$

$1-5$ years

6-10 years

11-15 years

16-20 years

21 years and over

Frequency of encountering a patient with a chest tube

Everyday

Almost everyday

Once a week

Biweekly

Once a month

Once a year

Never

Perception of knowledge level ${ }^{*}$

Sufficient

Partially sufficient

Insufficient

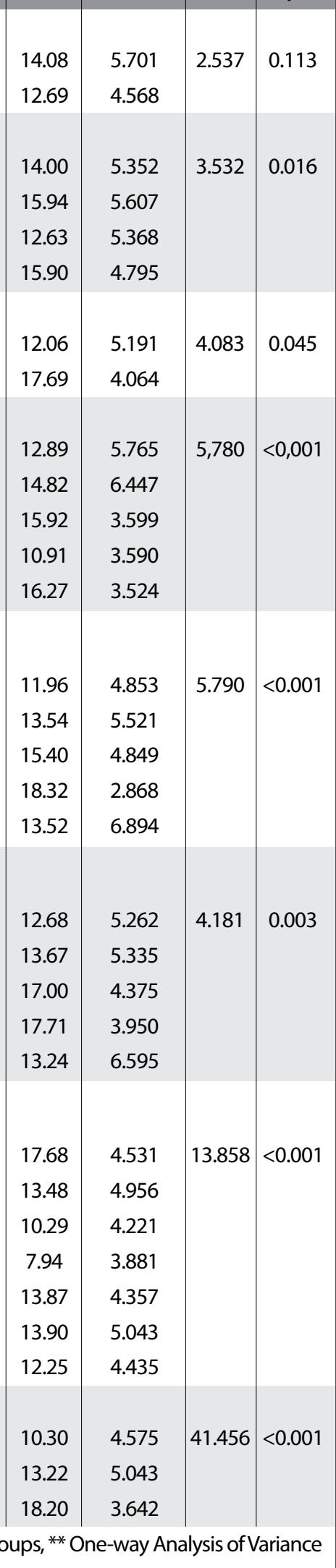




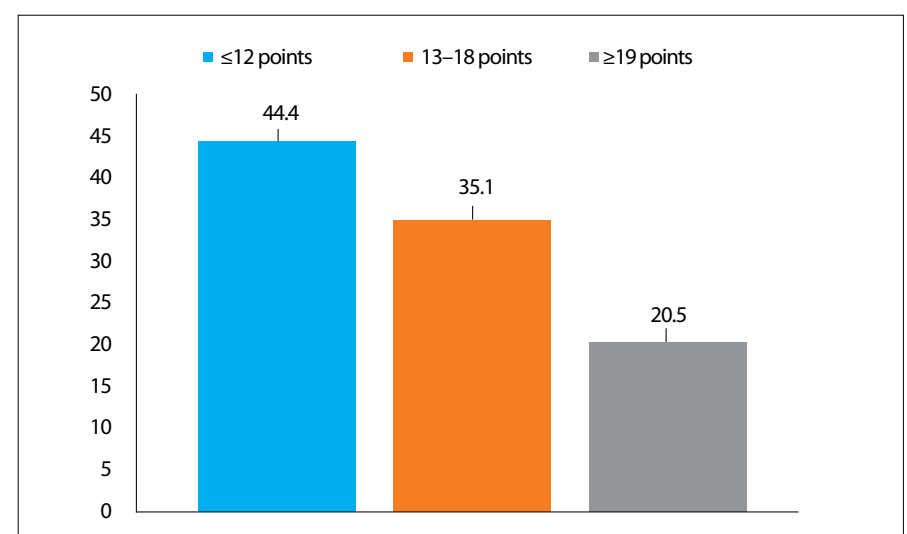

Figure 2. Distribution of points that the nurses scored from knowledge questions according to groups $(n=153)$

than those having other occupational experience durations; the difference between these scores was statistically significant $(p<0.001)$. It was found that there was a statistically significant difference between the institutional experience durations of the nurses and the mean scores that they obtained from the knowledge questions $(p<0.01)$. It was determined that this difference arose from the nurses having an institutional experience of 16-20 years, 1-5 years, and 6-10 years. It was observed that the nurses who encountered patients with chest tubes everyday and found their knowledge levels to be insufficient obtained statistically significant higher scores $(p<0.001$, Table 2$)$.

The number and percentage distributions of responses given by the nurses to the knowledge questions are summarized in Table 3. It was observed that the nurses had a sufficient knowledge level about the carriage of drainage bottles below the chest level (78.4\%), function of chest tubes (77.8\%), cases necessitating the insertion of chest tubes (75.2\%), and principles of intrapleural pressure and regular use of oral analgesic (71.9\%). In addition, it was observed that the questions regarding the use of analgesics during the insertion of chest tubes (38.6\%), use of prophylactic antibiotics (37.3\%), position of a patient during the insertion of a chest tube (37.3\%), performance of the Valsalva maneuver before the removal of a chest tube, and use of the chest tube drainage system were replied to less correctly (Table 3).

\section{DISCUSSION}

Nurses are responsible for the monitoring of patients with chest tubes, identification of potential problems, and provision of solutions. Based on the results of the present study, it has been observed that the knowledge level of the nurses for the management of patients with chest tubes is insufficient.

In the present study, while the knowledge level of $55.6 \%$ of the nurses was sufficient and intermediate, it was found to be insufficient in $44.4 \%$ of the nurses. In a study conducted in Ireland, it was found that the knowledge level of $78 \%$ of the nurses on the management of patients with chest tubes was sufficient and moderate (4). This finding shows that there is a need for training programs for nurses on the management of patients with chest tubes. The fact that only $2.6 \%$ of the nurses show school training as a source of knowledge regarding such patients reflects the lack in university education in this regard, which also emphasizes the need to include it in undergraduate and post-graduate education programs in nursing faculties or nursing high schools. In the present study, the fact that most nurses showed their colleagues to be the source of their knowledge underlines the requirement of continuous education for nurses in healthcare institutions. The knowledge levels of the nurses working in healthcare institutions on this subject can be enhanced by planning Internet-based or continuous education programs.

In the other studies conducted on the management of patients with chest tubes, the mean scores that the nurses obtained from the information questions and their descriptive and occupational characteristics were not compared $(4,6)$. The average scores obtained from the information questions involving the nurses who worked in the operating room and surgical units and who encountered patients with chest tubes every day were found to be higher in the present study. It was observed that the three findings of the present study are interdependent. The reason why the nurses with an occupational and institutional experience of 16-20 years obtained higher scores from knowledge questions can be explained by their possible working with different professionals for a longer duration and benefiting from their experience. The fact that the knowledge level is lower in the nurses with 1-5 years of professional and institutional experience reveals the need for the nurses with lesser experience to be supported by the nurses in supervisory roles. This support should also include the opportunity for the inexperienced nurses to participate in training programs. Training strategies should cover all the nurses in order to provide evidence-based care.

Sufficient knowledge of the nurses about the chest anatomy and physiology is very important to ensure timely and effective intervention when possible complications occur in patients with chest tubes. In the present study, while most nurses answered questions about intrapulmonary pressure correctly, expression about intrapleural pressure were incorrectly answered or as "I don't know" by half of the nurses. These findings are similar to the results of a study conducted on nurses in Ireland in 2013 (4). Nurses' understanding the principles of chest anatomy and physiology implies that the working principles of chest drainage system are also understood. Therefore, the expected training programs should include comprehensive issues of the chest anatomy and physiology.

Chest drainage can be required for several reasons. In thoracic surgery, it is performed to swell the collapsed lungs again, and the major indication is pneumothorax (7). In cardiac surgery, as a standard part of care, chest tubes are inserted in order to drain the serosanguinous fluid through the mediastinal or pleural cavity for the purpose of preventing complications such as cardiac tamponade (8). In the present study, the reason for the insertion of a chest tube into the pleural cavity is better known than that for the insertion of a chest tube into the mediastinal cavity, which can be attributed to the fact that the study was conducted in a hospital dealing with chest diseases. For the follow-up of any patient, it is very important for the nurses to know why the chest tube is inserted in the patient.

The third expression for which the least correct answer was provided by the nurses in the present study was related to the position of the patient during the insertion of the chest tube. While this question was answered correctly at a rate of $44.4 \%$ in the study of Lehwaldt and Timmins (6), it was answered correctly at a rate of $37.3 \%$ and as "I don't know" at a rate of $30.7 \%$ in the present study. During the insertion of a chest tube, the patient is usually on a bed and is positioned 
Table 3. Distribution of responses that the nurses gave to the expressions about the management of patients with chest tubes ( $\mathrm{n}=153$ )

\begin{tabular}{|c|c|c|c|c|}
\hline $\begin{array}{l}\text { True } \\
\text { responses }\end{array}$ & Expressions & True & False & $\begin{array}{l}\text { I don't } \\
\text { know }\end{array}$ \\
\hline True & $\begin{array}{l}\text { The fluid in the drainage bottle has to be kept } 90 \mathrm{~cm} \text { below the chest level in order to prevent } \\
\text { the fluid from entering the pleural space. }\end{array}$ & 78.4 & 6.6 & 15 \\
\hline True & The chest tube inserted to the pleural space provides reinflation of the collapsed lung. & 77.8 & 10.5 & 11.8 \\
\hline True & Pneumothorax is the most important case for which the insertion of a chest tube is necessary. & 75.2 & 11.8 & 13.1 \\
\hline True & Intrapleural pressure is the pressure in the pleural space. & 74.5 & 9.2 & 16.3 \\
\hline True & Regular oral analgesic use is effective in reducing the pain stemming from the chest tube. & 71.9 & 11.8 & 16.3 \\
\hline True & Gurgitation seen in the drainage bottle may be an indicator of air leak. & 69.9 & 15.7 & 14.4 \\
\hline True & $\begin{array}{l}\text { In inspiration, the lower end of the tube must be at least } 2 \mathrm{~cm} \text { inside water so that the } \\
\text { atmospheric air does not enter from the tube system into the pleural cavity. }\end{array}$ & 67.3 & 10.5 & 22.2 \\
\hline True & The movement of fluid by breathing in a chest tube is called oscillation. & 66 & 11.8 & 22.2 \\
\hline True & $\begin{array}{l}\text { The use of premedication during the insertion of a chest tube will reduce the pain experienced } \\
\text { by the patient. }\end{array}$ & 64.7 & 19 & 16.3 \\
\hline False & Drainage bottles should be changed every day in order to prevent respiratory system infections. & 63.4 & 25.5 & 11.1 \\
\hline False & Chest tube incision should be dressed only when it gets dirty. & 62.1 & 28.1 & 9.8 \\
\hline True & $\begin{array}{l}\text { The up and down movement of the fluid in the drainage bottle gives information about general } \\
\text { negative pressure. }\end{array}$ & 57.5 & 13.1 & 29.4 \\
\hline False & Intrapulmonary pressure is the pressure in the parietal cavity. & 52.3 & 23.5 & 24.2 \\
\hline True & $\begin{array}{l}\text { Chest tubes can be inserted into the mediastinum or pericardium for the purpose of preventing } \\
\text { cardiac tamponade. }\end{array}$ & 52.3 & 21.6 & 26.1 \\
\hline True & The level of suction should be generally arranged between $10-20 \mathrm{mmHg}$. & 50.3 & 15 & 34.6 \\
\hline False & There should not be any air bubble in the fluid in the bottle attached to the suction. & 49.7 & 25.5 & 24.8 \\
\hline False & Chest tubes should be removed during inspiration. & 46.4 & 31.4 & 22.2 \\
\hline False & Stripping and squeezing the chest tube routinely prevent the blockage of the tube. & 46.4 & 35.3 & 18.3 \\
\hline False & $\begin{array}{l}\text { The chest tube can be accidentally disconnected from the junctions during the movement of the } \\
\text { patient having air leak. Therefore, it has to be absolutely clamped. }\end{array}$ & 41.8 & 32.7 & 25.5 \\
\hline True & $\begin{array}{l}\text { A Heimlich valve can be inserted to the end of the catheter to increase the mobilization of the } \\
\text { patient, reduce the duration of the stay in hospital, }\end{array}$ & 39.2 & 22.9 & 37.9 \\
\hline False & $\begin{array}{l}\text { Additional analgesic should not be applied during the insertion of a chest tube because it can } \\
\text { cause shortness of breath. }\end{array}$ & 38.6 & 29.4 & 32 \\
\hline False & Prophylactic antibiotic should always be initiated for patients with chest tubes. & 37.3 & 36.6 & 26.1 \\
\hline False & $\begin{array}{l}\text { It is not appropriate for the patients to position toward the healthy lung during the insertion of } \\
\text { a chest tube. }\end{array}$ & 37.3 & 32 & 30.7 \\
\hline True & Patients must perform the Valsalva maneuver during the removal of a chest tube. & 34 & 28.1 & 37.9 \\
\hline False & Fluid accumulation to touch the short air tube in the drainage bottle is not a problem. & 27.5 & 46.4 & 26.1 \\
\hline
\end{tabular}

with the arms behind the head to facilitate intervention in the axillary area on the side of the affected lung (9). It is necessary to increase the awareness of nurses in this regard for patient safety. Therefore, training programs should include the responsibilities of nurses during the insertion of chest tubes.

After the chest tube is inserted into a patient, it should be connected to a drainage system. In drainage bottles, drainage is achieved using a long tube through the bottom of a bottle having at least $2 \mathrm{~cm}$ of water above the lower end of the tube. In order to prevent the ingress of atmospheric air into the pleural space, the lower end of the tube should be below the level of water and it should not be inside more than $3 \mathrm{~cm}$ of fluid to avoid resistance to drainage $(10,11)$.
A short air tube enables air to escape from the drainage bottle into the atmosphere, and fluid should not accumulate as high as this level in the drainage bottle (12). Among the expressions regarding long and short air tubes that form the basis of the functionality of the drainage system for effective treatment, although the expression regarding the functionality of the long air tube was known by $67.3 \%$ of nurses, the least correctly known expression in the survey was the one regarding the short air tube (27.5\%). In the present study, $25.5 \%$ of the nurses stated that the drainage bottles should be changed daily in order to prevent infections. All of the nurses in the study of Magner et al. (4) answered this statement correctly. Drainage bottles should be replaced only in the case of fluid accumulation or when they lose their functionality. 
The movement of fluid in the chest tube during breathing is called oscillation, and the up-and-down movement of this fluid provides information regarding the general negative pressure. If there is oscillation with the breathing movement, the tube is open; if not, the tube is closed or the lung is completely expanded (10). In the present study, these two statements were answered by almost half of the nurses, and the percentage of correct answers was similar. In the study of Magner et al. (4), the expression related to oscillation was correctly answered by $92.6 \%$ of the nurses, which is a considerable difference compared with the present study. Whether the chest tube is functional or not can be understood by observing the oscillations; this information is also vital in the follow-up of patients with chest tubes. Air bubbles can or cannot be seen in the drainage bottle (12). If the system is draining air, bubbles will occur; if it is draining only fluid, bubbles will not occur. If a system that is draining air does not create air bubbles, either the pneumothorax problem has been resolved or the tube is closed (13). If a drainage system stops creating bubbles, Gallon (14) suggests that the patient should take a deep breath or cough, considering the possibility of dislodgement or obstruction of the chest tube. The presence and absence of bubbles or any change that occurs should be written and reported. One of the key points in successful treatments and follow-up of patients with chest tubes is to know and understand the working of drainage systems. Evidence-based application should include technical information about drainage systems in addition to patient care. This is because knowing the clues in such a system will lead to the reduction of possible complications that may occur in patients and result in rapid improvement in patient outcomes.

There were three questions in the survey regarding applications that nurses should use in addition to informing the patient and relatives. The first question was related to the clamping of the chest tube. The chest tube must not be clamped in a patient with an air leak or during the transfer of a patient. It can be clamped for a short time only during the replacement of the drainage bottle or during the discharge of the inside fluid (15). While the statements aimed at clamping were correctly answered by $72 \%$ of the nurses in the study of Lehwaldt and Timmins (6) and by $38.8 \%$ of the nurses in the study of Magner et al. (4), this rate was $41.8 \%$ in our study. Because clamping or not clamping is an issue of daily practice for nurses, it is essential to resolve this issue. At the same time, in addition to knowledge, studies researching the extent to which nurses use this application in daily practice are urgently needed. Another expression was related to the milking of the chest tube. Stripping is compressing the chest tube between the thumb and index finger of one hand and pulling the fluid or clots from the chest wall toward the drainage bottle with a downward motion with the other hand. The milking process includes freely squeezing without any pressure, bending, and kneading for the same purpose (16). In contemporary studies, intrathoracic pressure was observed to rise up to $-400 \mathrm{~cm} \mathrm{H}_{2} \mathrm{O}$ by the application of stripping $(17,18)$. The milking or stripping applied to the chest tube did not generally increase the amount of chest drainage $(16,18,19)$. In another study, it was observed that $71 \%$ of nurses stated that stripping was not allowed; however, $74 \%$ of surgeons favored this practice (20). In the study, $35.3 \%$ of the nurses marked the expression regarding routinely milking and stripping the chest tube in order to prevent tube clogging as the correct answer. The ratio of the same expression was $29.6 \%$ in the study of Lehwaldt and Timmins (6). The fact that the literature does not provide a clear description on this subject sug- gests that uncertainty and confusion may have reflected to the practice. The care of patients with chest tubes should be discussed with regard to advice and scientific knowledge from national and international guidelines in order to standardize the care of these patients and evaluate evidence-based nursing practice. In all the studies, the expression related to secure application was known by most nurses (78.4\%). In the study of Magner et al. (4), this expression was correctly known by almost all the nurses. Secure application involves keeping the drainage bottle below the chest to prevent the ingress of air and fluid into the pleural space (9). Nurses should explain the reason for which drainage bottles should be kept in such a position to patients and their families, ensuring awareness on this issue.

In addition to the knowledge regarding removing the chest tube at the end of inspiration and performing the Valsalva maneuver while removing the tube, there were two questions in the survey that assessed the knowledge of nurses regarding the removal of the chest tube. The British Thoracic Society Guideline recommends that the chest tube should be removed while the patients perform the Valsalva maneuver or during expiration (21). This information was considered to be accurate while preparing the questionnaires. When the literature was taken into consideration, some authors found it appropriate to remove the chest tube at the end of expiration, during the Valsalva maneuver, or at the end of inspiration. In one study, the removal of the chest tube at the end of inspiration and at the end of expiration was compared, and the Valsalva maneuver was performed in both these groups. No difference was observed between these two groups in terms of the risk of pneumothorax (22). Experimental studies are needed in this regard for the elimination of technical differences, standardization of treatment and care, and use of a valid and reliable method.

Pain management in patients is very important during the insertion and removal of the chest tube and during the time between these two processes. In a study conducted in 1998, Luketich et al. (23) found that the insertion of a chest tube resulted in high levels of pain and anxiety in patients; therefore, they developed a protocol involving patient education, technical issues, local anesthetics, and premedication for the purpose of reducing pain. In general, it is a likely outcome that the nurses who assist in the insertion of a chest tube accurately answer questions about premedication at a higher proportion. The number of correct, wrong, and "I don't know" answers of the nurses to the statement "During the insertion of a chest tube, additional analgesics may cause shortness of breath and thus should not be administered" were fairly similar. The decision regarding the requirement of premedication during the insertion of a chest tube and pain management until then rests with the physician. However, the nurse is responsible for the management of pain during the time between the insertion and removal of the chest tube. After the insertion of the chest tube, nurses should often evaluate the pain levels and effectiveness of the pain relievers (13).

Avery (9) argued that the incision of the chest tube should be checked and monitored for the signs of infection and daily records should be maintained. Lehwaldt and Timmins (6) also supported this view in their study. However, Magner et al. (4) accepted the statement related to daily dressing changes as incorrect. In the present study, the view of the need for daily dressing on the incision of the chest tube was accepted, and $62.1 \%$ of nurses correctly responded to 
this statement. Different opinions exist with regard to dressing applications of patients with chest tubes. In order to ensure standardized nursing care, there is need for extensive experimental clinical studies at this point.

Another important issue is the use of prophylactic antibiotics before the insertion of the chest tube. In a study conducted in 2006, the use of prophylactic antibiotics was found to significantly reduce the risk of pneumonia and empyema in traumatic patients (24). In another study conducted in patients with pneumothorax, prophylactic antibiotic use was found unnecessary (25). The British Thoracic Society Guideline that has been considered as a guide in the preparation of our survey recommends the use of prophylactic antibiotics in traumatic patients. Therefore, the opinion of continuously administering prophylactic antibiotics to patients with chest tubes has been recognized as wrong. In our study, $37.3 \%$ of nurses answered this correctly, and this rate is higher than that in Magner et al. (4).

\section{Study Limitations}

The present study was conducted in a single hospital dealing with chest diseases. The data were collated through a single questionnaire form, and only theoretical information was evaluated. Future studies should investigate the applications of nurses in this subject through observations and explain the results of patients that are affected by these applications.

\section{CONCLUSION}

The knowledge levels of almost half of the nurses regarding the management of patients with chest tubes are insufficient. Both nurse managers and nurse academicians should discharge their responsibilities in order to provide and pursue continuing education programs regarding caring for patients with chest tubes. Meanwhile, national and international guidelines delineating the roles and duties of nurses in the care for patients with chest tubes should be developed with the support of clinical experimental studies in order to eliminate the differences in the literature and standardize patient care.

Ethics Committee Approval: Authors declared that the research was conducted according to the principles of the World Medical Association Declaration of Helsinki "Ethical Principles for Medical Research Involving Human Subjects", (amended in October 2013).

Informed Consent: Verbal informed consent was obtained from all of the nurses who participated in this study.

Peer-review: Externally peer-reviewed.

Author Contributions: Concept - M.T., S.A.G., A.A., L.D.; Design - M.T., S.A.G., A.A.; Supervision - M.T., S.A.G.; Resources - M.T., A.A.; Materials - M.T., S.A.G., A.A., L.D.; Data Collection and/or Processing - M.T., S.A.G., A.A.; Analysis and/or Interpretation - M.T., S.A.G.; Literature Search - M.T., L.D.; Writing Manuscript M.T., S.A.G., A.A., L.D.; Critical Review - M.T., S.A.G., A.A., L.D.; Other - M.T., S.A.G., A.A., L.D.

Conflict of Interest: No conflict of interest was declared by the authors.

Financial Disclosure: The authors declared that this study has received no financial support.

\section{REFERENCES}

1. Kuhajda I, Zarogoulidis K, Kougioumtzi I, Huang H, Li O, Dryllis G, et al. Tube thoracostomy; chest tube implantation and follow up. J Thorac Dis 2014; 6: 470-9.

2. Zisis C, Tsirgogianni K, Lazaridis G, Lampaki S, Baka S, Mpoukovinas I, et al. Chest drainage systems in use. Ann Transl Med 2015; 3: 43-52.

3. Charnock Y, Evans D. Nursing management of chest drains: a systematic review. Aust Crit Care 2001; 14: 156-60. [CrossRef]

4. Magner C, Houghton C, Craig M, Cowman S. Nurses' knowledge of chest drain management in an Irish Children's hospital. J Clin Nurs 2013; 22: 2912-22. [CrossRef]

5. Godden J, Hiley C. Managing the patient with chest drain: a review. Nurs Stand 1998; 12: 35-9. [CrossRef]

6. Lehwaldt D, Timmins F. Nurses' knowledge of chest drain care: an exploratory descriptive survey. Nurs Cri Care 2005; 10: 192-200. [CrossRef]

7. Durai $\mathrm{R}$, Hoque $\mathrm{H}$, Davies TW. Managing a chest tube and drainage system. AORN J 2010; 91: 275-80. [CrossRef]

8. Le J, Buth KJ, Hirsch GM, Legare JL. Does more than a single chest tube for mediastinal drainage affect outcomes after cardiac surgery? Can $J$ Surg 2015; 58: 100-106.

9. Avery S. Insertion and management of chest drains. Nursing Times Plus 2000; 96: 3-6.

10. Yıldızeli B, Yüksel M. Plevra hastalıklarında cerrahi teknikler. Turk Thorac J 2002; 3: 30-44.

11. Sullivan B. Nursing management of patients with a chest drain. Br J Nurs 2008; 17: 388-93. [CrossRef]

12. Gökçe Işıklı A. Kapalı su altı dreninde hasta deneyimlerinin belirlenmesi. Trakya Üniversitesi, Hemşirelik Anabilim Dalı, Yüksek Lisans Tezi, Edirne.

13. Woodrow P. Intrapleural chest drainage. Nurs Stand 2013; 27: 49-56. [CrossRef]

14. Gallon A. Pneumothorax. Nurs Stand 1998; 13: 35-9. [CrossRef]

15. Ergin $M$, Yeğinsu A, Gürlek K. Göğüs tüpünün takılması. Ulus Cerrahi Derg 2010; 26: 115-21.

16. Halm MA. To strip or not to strip? Physiological effects of chest tube manipulation. Am J Crit Care 2007; 16: 609-12.

17. Duncan C, Erickson R. Pressures associated with chest tube stripping Heart Lung 1982; 11: 166-71.

18. Day TG, Perring RR, Gofton K. Is manipulation of mediastinal chest drains useful or harmful after cardiac surgery? Interact Cardiovasc Thorac Surg 2008; 7: 888-90.

19. Wallen M, Morrison D, Gillies D, O'Riordan E, Bridge C, Stoddart F. Mediastinal chest drain clearance for cardiac surgery. Cochrane Database Syst Rev 2004: 4

20. Shalli SI, Saeed D, Fukamachi K, Gillinov AM, Cohn WE, Perrault LP, et al. Chest tube selection in cardiac and thoracic surgery: a survey of chesttube related complications and their management. J Card Surg 2009; 24: 503-9. [CrossRef]

21. Laws D, Neville E, Duffy J. British Thoracic Society Guidelines for the insertion of a chest drain. Thorax 2003; 58: 53-9. [CrossRef]

22. Bell RL, Ovadia P, Abdullah F, Spector S, Rabinovici R. Chest tube removal: end-inspiration or expiration? J Trauma 2001; 50: 674-7.

23. Luketich JD, Kiss M, Hershey J, Urso GK, Wilson J, Bookbinder M, et al. Chest tube insertion: a prospective evaluation of pain management. Clin J Pain 1998; 14: 152-4. [CrossRef]

24. Sanabria Al, Valdivieso E, Gomez G, Echeverry G. Prophylactic antibiotics in chest trauma: a meta analysis of high-quality studies. World J Surg 2006; 30: 1843-7. [CrossRef]

25. Olgac G, Aydogmus U, Mulazimoglu L, Kutlu CA. Antibiotics are not needed during tube thoracostomy for spontaneous pneumothorax: an observational case study. J Cardiothorac Surg 2006; 1: 43-6. [CrossRef] 